Article

\title{
Actualizing Unique Type and Token Values as a Solution to the Problem of Evil
}

\author{
Atle Ottesen Sovik \\ Department of Systematic Theology, MF Norwegian School of Theology, P.O.Box 5144 Majorstuen, \\ 0302 Oslo, Norway; Atle.O.Sovik@mf.no; Tel.: +47-2259-0536
}

Received: 30 November 2017; Accepted: 22 December 2017; Published: 24 December 2017

\begin{abstract}
Concerning the problem of evil, I suggest that God's goodness and omnipotence causes God to want to actualize many different values and things, not solely angels in heaven, but also type unique values like independence, self-formation, creativity, and surprise, and token unique goods like animals and human beings. Such a universe as ours, though, requires undisturbed indeterministic self-formation as actualized by a good God to give those token unique beings access to those type unique values and allow them the opportunity to live forever with God after completion of this self-formation.
\end{abstract}

Keywords: the problem of evil; type and token values; indeterminism

\section{Introduction}

In this article I suggest the following solution the problem of evil: God is good and omnipotent, and as good, God wants to actualize many and many different values in the world. More precisely, God wants to actualize values that are type unique in being different kinds of good, and token unique in being instantiations of values at different times and places. This has the consequence that God not only wants to create a heaven with angels and no suffering, but also a universe like ours, which actualizes type unique goods like independence, self-formation, creativity, and surprise, and token unique goods like the actual animals and humans that live here. Bringing forth a universe like ours requires indeterminism, which also has the negative effect that suffering becomes possible. There is no other way to bring about a highly independent, self-formed, creative and surprising universe with the token unique individuals living there than through undisturbed indeterministic self-formation. This is the only way for the individuals living there to come into being and have the opportunity to live forever with God (after self-formation), and thus it is good that God actualizes such a universe.

In the following, I shall unpack these claims and defend them against objections. I have previously written a book on the problem of evil defending a similar theory (Søvik 2011). In the book I focused on independence, but here the focus is instead on actualizing type and token unique values, which was not a distinction made in the book. I have not seen anyone else use this distinction to solve the problem of evil. The discussion of types of values, their relation, and why God would actualize these is new to this article.

The article is divided into four parts. Part one is the introduction. In part two, I start by discussing how to understand values and the distinction between type and token unique values. I then argue that the goodness of God implies that God wants to actualize many and many different types of values. In part three, I present some specific values that I suggest God wanted to actualize in our universe, and what the conditions are for bringing forth such values. I end this part by arguing that it is good for God to create our universe with these conditions. In part four, I answer objections. 


\section{Values}

How should values be understood? In meta-ethics, cognitive realists hold that moral judgments are beliefs that can be true. This means that there are true statements of the form " $\mathrm{X}$ is good", "X is just", etc. Among cognitive realists, there are three different groups offering three different explanations as to what gives moral judgments truth value; the supernaturalists, non-naturalists and naturalists. Supernaturalists refer to the mind of God to explain the truth value of moral judgments, so it is true that $X$ is good if $X$ is the will of God. Non-naturalists refer to values having their own (platonic) existence, or at least as being something which cannot be given a naturalistic definition, as famously argued by G. E. Moore (Moore and Baldwin 1903, § 13). Naturalists argue that values are something natural, for example, that what is good is that which produces the most pleasure (Bentham 1988, chp. 1).

The classical objection to supernaturalists is the Euthyphro dilemma: is something good because God wants it, or does God want it because it is good? (Allen and Plato 1970, part two). The classical objection to non-naturalists is that such values are queer entities, and that it is more plausible to believe that they do not exist (Mackie 1977). Classical objections to naturalism are Moore's open question argument and that naturalism seems to take the normative force out of ethics (presented further below).

There is not room in this article to discuss the ontology of values, but I will offer a brief defense for a naturalistic approach. This naturalistic approach avoids the Euthyphro dilemma. It also avoids the objection of queerness, since there are no queer entities. It further has the advantage of explaining ethical supervenience. All seem to agree that ethical facts supervene upon descriptive facts, in the sense that there cannot be an ethical change without a descriptive change. Differently put, there cannot be two identical universes except that in one of them murder is wrong and in the other murder is good. But this seems to favor a descriptive understanding of norms. For if values are something that have their own existence, it seems we should be able to have two identical universes, except that we add one value to one of them. How are values connected to the natural world if they are not identical to something natural?

Moore's open question argument against naturalistic ethics is as follows: It is a fallacy to give a descriptive definition to the term "good", since it is always an open question whether the definition given is actually good. For example, if "good" is defined as that which maximizes pleasure, we can still openly and meaningfully ask whether that which maximizes pleasure is good. According to Moore, this showed that the term "good" could not be given a descriptive definition.

Several counterarguments have been offered against Moore. It is meaningful to ask whether $\mathrm{H}_{2} \mathrm{O}$ is water even if (most) water is $\mathrm{H}_{2} \mathrm{O}$. The argument is question-begging since it assumes that any definition of "good" is not right, and the argument proves too much since it seems that we can meaningfully discuss many definitions of terms (like knowledge) without concluding that they are undefinable. I believe that the reason we feel that we can meaningfully ask of any definition of "good" whether it is good is that we have a vague/general/non-conscious intuition about what goodness is. It does not follow that there is actually more to say, or something undefinable about it, or a correct answer beyond how we choose to define the term.

When it comes to Hume's charge that one cannot derive an ought from an is, the naturalist can respond that the "ought" has been given an "is" definition, so that ethical norms derive an is from an is. But if ethical norms are given descriptive content, it seems to take away the normative force of these ethical norms. Ethical norms commend or prescribe a certain action; they motivate people for action. How could this be understood if what is good is something natural?

This "normative force" can be understood in different ways. In itself, a should claim or an ought claim is a means to reach something considered good. Thus, when saying that people should or ought to do a moral act, it means that if they want to reach something good, then that is a means to that goal. But that alone does not seem to commend the goal in a way that normative claims seem to commend actions for people.

I believe that this commending aspect comes from people saying that something is good or should be done. If one accepts that something is good or should be done, one accepts that this is something 
one ought to try to reach. Different people will feel different degrees of normative force when facing different norms. If there is a God, most people would probably feel an extra weight from the fact that something was willed by the omnipotent creator of the universe, but even this could be rejected.

This may still seem too weak. Is there a normative force regardless of what people think or feel? Can we say that objectively you have reason to act in such and such ways, regardless of whether you want to or not? You cannot have a reason without a goal. It is the good as a goal that gives us reason to act, but that presupposes the goal first. Of course, there can be many reasons for acting morally-that it is good, that it is consistent and rational, that it is in your own self-interest, etc. These reasons will give different force to normative claims, but there is no ontological normative force coming from ethics itself beyond what is described here.

This was a brief and general defense of a naturalistic approach, which is also more ontologically parsimonious than non-naturalism and supernaturalism. However, the theodicy to be presented below does not depend on one accepting naturalism about values as long as one accepts ethical supervenience. A defense of this approach is nevertheless included in order to present a detailed theodicy.

After this general defense of naturalism about values, the time has come to ask what values are. In line with the goal of parsimony, I suggest that value or something good should just be understood as anything that is valuated/appreciated/considered good by anyone. However, we should distinguish between three different meanings of the term value/good, where the basic meaning is that something is good in the sense that it is valuated by an individual, and we could refer to this valuation as individual-good. This is then to distinguish from ethical-good, which is when we try to sum up all the individual-goods into what would be valuated most by the most. And this again could be distinguished from the sense in which the things or events being valuated are good, which we could call potential-good, since the value of something lies in its potential for being valuated by someone.

These different aspects of what is good relate in the following way: The most fundamental part is that someone valuates something. When someone valuates something-not instrumentally, but for its own sake-this does not have a deeper explanation than to just be valuation. I may watch comedies because I like to laugh, and there is no deeper explanation for why I like to laugh-I just like it. This valuation (individual-good) is the basis for ethical-good, since ethical-good is the most individual-good for the most individuals. And this valuation (individual-good) is also the basis for the value that things, people and events have (potential-good). That does not mean that something does not have value if it is not valuated, but that it would not have value if no valuation existed at all.

Again, there is no room to discuss this definition of values in this article, but I include it as a precise presentation of what values are. I now move on to the distinction between unique type and token values. A type value is a value that can be instantiated at several times and places, e.g., joy. A type value is unique if it has intrinsic properties different from other values, e.g., fun is a type unique value in virtue of having different intrinsic properties than peace, love etc. ${ }^{1} \mathrm{~A}$ token value is an instantiation of a type value at a certain time and place, e.g., the joy of attending the party yesterday at my neighbor's house. Thus, the joy I experience as I write this article is token unique from my joy yesterday at the neighbor's house.

Having now defined values and the distinction between type and token values, the next question is whether God would want to actualize many and many different type and token values. One could imagine that God only created one type of potential good, such as harp music or clouds, and then just created one type of individual who could valuate it, such as angels. God could then increase the amount of potential good and individual good by increasing the number of clouds or harp songs or angels or the amount of time, and this would be ethically good since it brought about more individual good.

God could also increase the number of type values, creating different potential goods, such as stars. This would bring about more variation in what could be valuated, and the variation in itself

1 The term "intrinsic properties" here refers to all characteristics other than spatio-temporal location. 
would be a good that could be valuated. God could also create different kinds of individuals that could valuate different kinds of things, like animals and humans. These different types of individuals could valuate not only different things, but also each other. Again this would be an ethically good increase of individual good in the world. In addition, it would be sharing of goods in a relationship, which is also ethically good.

However, it is not necessarily ethically good just to create as many individuals as possible, since it depends on how their lives are overall. What we have seen so far is that it is prima facie ethically good of God to actualize many types of potential goods and many types of individuals who can valuate the goods and the variation itself, but there are other relevant things to consider as well in order to judge whether God's creation is good, for example, the place of suffering. In the next part, we shall make such a broad consideration of our universe.

\section{Our Universe}

God could have created animals and humans in many different ways. They could have been created without capacity for suffering. Perhaps God already has created such individuals in another universe, and at least it is a part of Christian faith that humans will have an afterlife which is like that-and some include animals in that vision.

The theodicy presented in this article suggests that God in our universe has actualized the following unique type values: The universe is independent in the sense of a partly self-creating universe which brings forth living individuals in a creative and surprising way, and these individuals are also independent in the sense of being partly self-creating. The individual animals and humans in this universe are themselves token values of a certain type, as just described.

The mentioned type values come in degrees: there can be different degrees of how independent, self-creating, creative and surprising something is. This theodicy proposes that these values come in a high degree in our universe: it is independent, self-creating, creative and surprising to a high degree.

The mentioned values have a common requirement, which is indeterminism. Indeterminism denies that the world is determined, which would mean that there is only one possible content of the future. Instead, indeterminism means that the content of the future is open. There can be different reasons why the universe should be determined, such as laws of nature, God, destiny, or something else. There can also be different reasons why the universe should be indetermined, such as causeless events, probabilistic laws of nature, or something else.

Even if the universe is indeterministic, it is not given what space of possibilities such indeterminism happens within. The future can be open but with a very limited set of possible futures, or it can be very open with a great variety of possible open futures. For example, indeterminism could be confined to the micro level of quantum physics or also apply to the macro level of human interaction, and it could have all sorts of other constraints.

The theodicy here presented proposes that our universe is genuinely indeterministic, which means that it occurs within a large space of possibilities. God knows what the possibilities are, but does not know which possibilities will be actualized. This genuine indeterminism gives the universe its high degree of independence, self-creation, creativity, and surprise.

While indeterminism is a condition that makes these mentioned values possible, genuine indeterminism has the negative side effect that it makes suffering possible. It can cause mutations and diseases, and it can cause natural disasters such as storms, earthquakes, volcanic eruptions etc. As a condition for a strong degree of libertarian freedom, it can also make people abuse this freedom to cause others pain. In order to be used as an explanation for suffering, indeterminism cannot be very restricted, but must have occurred within a large space of possibilities from the beginning of the universe. In addition, God's goal of a highly independent universe must make God generally refrain from interfering.

We shall consider many objections below, but here I ask the following question: Do we have reason to believe that our universe is genuinely indeterministic? The most common place to go for 
support is quantum mechanics. Quantum mechanics can be given indeterministic interpretations (like Copenhagen and GRW) and deterministic interpretations (like deBroglie-Bohm and Everett). Nevertheless, all interpretations will agree that the guiding laws are merely probabilistic, saying only that something will occur with a certain probability (Ney and Albert 2013). This still leaves open whether there is a determinism at a deeper level and whether indeterminism at the micro level of elementary particles can be scaled up to the macro level of human interaction.

James Ladyman argues that micro indeterminism obviously can be scaled up to the macro level of humans since humans interact with quantum indetermined processes. For example, a scientist may decide to invite his female colleague to lunch if he gets a click on his Geigerteller before 12 o'clock. Geigerteller clicks are undetermined events, and this decision may make them have lunch, fall in love and get married-or not. The world may then be very different in the future depending on undetermined events (Ladyman et al. 2007, p. 264).

However, one can also turn to classical Newtonian physics to find support for indeterminism at the macro level of human interaction. In such physics, indeterminism at the macro level occurs, for example, if three identical particles with the same speed collide (Earman 1986, pp. 30-32). ${ }^{2}$ The question of whether our universe is deterministic or not will probably never be given a certain answer since there could always be a deeper level we have not discovered. But for the time being, there seems to be more support for indeterminism than determinism.

When it comes to the space of possibilities within which indeterminism takes place, it is hard for science to say much. When I propose that this is a large space, it must be considered as a metaphysical hypothesis, to be judged by the coherence of the worldview it implies. As explained above, this theodicy needs the space of possibilities to be large in order for indeterminism to work as an explanation of suffering.

The time has come to consider whether it would be good of God to actualize the mentioned values in our universe on the condition that indeterminism can cause suffering that God does not prevent. It is commonly said that a theodicy must meet two requirements: the necessity condition and the outweighing condition (Wahlberg 2015, p. 38). The possibility of suffering must be shown to be a necessary means to a sufficiently outweighing good.

When it comes to the necessity condition, this theodicy only works on the presupposition that substance ontology should be replaced by an ontology that prioritizes relations, such as relational ontology, structuralistic ontology, process ontology, or trope ontology. If substance ontology is right, what gives individuals their identity is fundamentally the substance that they are, and God could have actualized this substance in another universe. In other words, if substance ontology is right, God could have created you or me in another universe or directly into heaven.

If substance ontology is wrong, however, and one of the mentioned alternative ontologies are right, then what makes us into the individuals we are are our life stories and relations. Then I could not have had other parents, since other parents would not have given birth to me, but to another. And God could not have created me in another universe or directly into heaven since what makes me into me is the fact that I was born when I was, by those parents, and have formed my life through the events and relations that I have.

In other words, for God to actualize the token individuals of our universe, of the type that they are, God had to create a genuinely indeterministic universe governed by laws and independent from God's interventions, such as our universe is. We cannot complain that God should have created us in another universe since this would be logically impossible.

This claim requires also that it is not God who decides whether substance ontology or relational ontology is the correct metaphysics of the world, but that this is a fundamental fact about reality,

2 Earman also gives other examples from Newtonian and relativity physics. Important examples are briefly summarized in (Sklar 1992, p. 203). 
including God. There must necessarily be several facts about the world that are not the result of God's will, since God could not have chosen God's own being before God's own existence. That there are structures in reality that are not chosen by God is thus a logically necessary part of any theory of God.

The possibility of suffering is thus a necessary requirement for bringing about the individuals of this universe, and the outweighing good is the eternal life of happiness that God offers us after death. God could not ask us before we were born if we wanted to come into existence on these conditions, but had to make the choice for us. God knows that the suffering can be outweighed, and hopefully God also knows that we will think that it was worth it.

The theodicy here offered is the theory that God could only actualize the token and type values of this universe by creating this kind of universe, and that the suffering will be outweighed in the afterlife. It is argued that it is good of God to actualize many different type and token values. While God could just have created angels in heaven, God chose to actualize more types of individuals who could valuate more types of goods. This lets God valuate more types of good as well, such as having another kind of relationship with another kind of individual. Since this is our only possibility to have an eternal life with God, it is good for us that God created us—even on the condition that suffering is possible-and thus it is good that God created our universe.

\section{Objections}

There are plenty of objections that could be raised against this theodicy, and there is only room to answer the main objections. I will discuss some objections which apply to theism in general, and some objections which apply to a Christian concept of God in particular. The objections are the following: God could have reached the same goals without giving us libertarian free will and then indeterminism would not have been necessary; genuine indeterminism contradicts that God knows the future; animals suffer without having their suffering outweighed; offering a theodicy is immoral; God could have created a universe with indeterminism but where pain and suffering were nevertheless impossible; the theodicy does not explain the hiddenness of God; if not all are saved, some people will not have their suffering outweighed; since God did many miracles in the time of Jesus, God should prevent more suffering now; there is no support in the Bible that God wanted to create such an independent universe; God wants relationship with humans and not to leave them alone. Since I do not have space for a full discussion of these objections, I will briefly indicate my response in order to show the direction that a larger defense could take. Most of these objections are discussed in my book on the problem of evil (Søvik 2011).

Could not God have reached the same goals without giving us libertarian free will? Then indeterminism would not have been necessary? God could have created a universe which was determined and where we had only compatibilist free will. This would have been a weaker form of free will, since whatever happened would be determined before we were born. The universe would have contained different values, since it would have been less independent and less surprising, and it would have contained different token individuals. God could have done so, and could have created a good universe, and maybe God has. But the argument here is that God did not have to choose between making us and someone else, but that it is good that God has created us in addition to the good heaven-world and all the other universes God may have created.

Does not genuine indeterminism contradict that God knows the future? This theodicy implies that God does not know the future. That raises a lot of questions which cannot be discussed here, but there is a rich literature discussing the topic of God and time. I side with those who defend an understanding of God in time, such as Richard Swinburne, or the position of open theism.

Do animals suffer without having their suffering outweighed? We do not know which animals have a conscious experience of being an individual over time, which makes them capable of conscious suffering. It may seem obvious which animals suffer, but contrary to appearances, almost all actions can occur non-consciously, so it is not obvious which animals suffer. Anyway, God knows, and this 
theodicy does not work unless animals which experience being individuals over time also get a good afterlife, and so this is presupposed.

Is it not immoral to offer a theodicy? Offering a theodicy can sometimes create more suffering for people who suffer. But other times it can give comfort and hope to people who suffer. Searching for truth in itself is not immoral, but one must be context sensitive when actually presenting a theodicy to someone. Not publishing theodicies at all since sufferers might get hurt by them is not a good enough reason, since pursuit of truth and the possibility of helping sufferers are good consequences of publishing theodicies. There are obviously better ways to help sufferers than to publish theodicies, but it is not wrong to publish a theodicy even if there are other things that are more important.

Could not God have created a universe with indeterminism but where pain and suffering were nevertheless impossible? I wrote above that God created in our universe the space of possibilities that indeterminism takes place within, but I also wrote that there are some basic structures of the world that God has not created. That suffering at all is possible in the world is not a choice made by God. God cannot have chosen the basic possibilities of the world, since the basic possibilities must be there in order for anything to be actual at all.

God has chosen the restrictions that apply to our universe, but it seems plausible to me that there is a necessary link between genuine indeterminism and the possibility of pain and suffering, given genuine indeterminism. This means that God could have restricted indeterminism so much in our universe that pain and suffering could never occur. But this would have been a very limited indeterminism. If God wanted a high degree of independence in our universe, it would require an indeterminism with few limits, and then pain and suffering is one of the possibilities that genuine indeterminism can actualize.

Does this theodicy explain the hiddenness of God? The hiddenness of God is explained by the independence of the universe that God wanted to actualize. The independence of this universe is again explained by this being one of the many diverse values that God wants to actualize here while actualizing other types of values elsewhere. Many discussions of the hiddenness of God assume that God chooses, from situation to situation, to hide, whereas this theodicy makes it a part of the choice God made from creation on. I find such a choice by God far easier to defend than to claim that God should have reasons to hide from situation to situation.

Will some people not be saved, and then not have their suffering outweighed? This theodicy does not presuppose that all have an afterlife, since some may want not to live forever. But it does presuppose that all who have a capacity for freely choosing to reject God get a real choice to do so. Hopefully, none will choose that, but I leave the possibility open. As long as all have a real opportunity to have their suffering outweighed, this seems enough to defend the goodness of God.

If God did many miracles in the time of Jesus, why does not God prevent more suffering now? While God wanted to create an independent world, God also wanted there to be a trustworthy revelation available for those who seek it. God thus had a strong reason for offering a revelation and verifying it as a revelation from God by putting a divine signature on it in the form of miracles-especially the resurrection of Jesus. A high degree of independence does not mean that God can never intervene, but it does mean that God can almost never intervene.

If God can intervene, why does not God intervene in the worst cases of suffering? God has created a very independent universe with indeterminism playing a big role even from the beginning of the universe. Intervening to prevent great evils is a big intervention with great consequences for everything that happens later, and there are many great evils that should be prevented if God prevented all evils of a kind. Our universe has a degree of indeterminism and independence where God does not make such interventions. It would certainly have been easier to believe in the existence of God if our universe was different in this regard.

Is there any support in the Bible that God wanted to create such an independent universe? Gen 1: 26-28 says that humans are created in the image of God, and that God asked them to dominate the earth. 
Since we are in fact highly independent, it is a coherent interpretation of the Bible to think of this as the will of God.

Does not God want relationship with humans and not to leave them alone? Relationship with humans is the ultimate goal for God, but in our universe there is an independent period first where, to a large degree, we shape our own lives. We may use our independence to seek and have relationship with God, but again, to a large degree, God remains hidden as long as the universe continues in the conditions it works under today.

\section{Conclusions}

The possibility of suffering in our universe can be explained by God wanting to actualize many different type and token values, and that among the values actualized in our universe are independence, self-formation, creativity, surprise and the token individuals of this universe. This solution has many presuppositions, among the more important being that there is genuine indeterminism in our universe, that there is an afterlife for humans and animals, and that substance ontology is wrong. These presuppositions have been briefly defended in this article which, although brief, offers a new theodicy to the larger discussion.

Conflicts of Interest: The author declares no conflict of interest.

\section{References}

Allen, Reginald E., and Plato. 1970. Plato's 'Euthyphro' and Earlier Theory of Forms, International Library of Philosophy and Scientific Method. London: Routledge \& K. Paul.

Bentham, Jeremy. 1988. The Principles of Morals and Legislation. Great Books in Philosophy Series; Buffalo: Prometheus Books.

Earman, John. 1986. A Primer on Determinism. University of Western Ontario Series in Philosophy of Science; Boston: D. Reidel Pub. Co.

Ladyman, James, Don Ross, David Spurrett, and John Gordon Collier. 2007. Every Thing Must Go: Metaphysics Naturalized. Oxford: Oxford University Press.

Mackie, John L. 1977. Ethics: Inventing Right and Wrong. Pelican Books: Philosophy; New York: Penguin.

Moore, George Edward, and Thomas Baldwin. 1903. Principia Ethica. Cambridge: Cambridge University Press.

Ney, Alyssa, and David Z. Albert. 2013. The Wave Function: Essays on the Metaphysics of Quantum Mechanics. Oxford: Oxford University Press.

Sklar, Lawrence. 1992. Philosophy of Physics. Dimensions of Philosophy Series; Boulder: Westview Press.

Søvik, Atle Ottesen. 2011. The Problem of Evil and the Power of God. Studies in Systematic Theology. Leiden: Brill.

Wahlberg, Mats. 2015. Was Evolution the Only Possible Way for God to Make Autonomous Creatures? Examination of an Argument in Evolutionary Theodicy. International Journal for Philosophy of Religion 77: 37-51. [CrossRef] 